\title{
Top-Down Processing: A Network Analysis of The Lord of the Rings as a Means of Defining Good and Evil
}

\author{
Dennis Werbicki
}

Department of English \& Film Studies, University of Alberta, Edmonton, Alberta

Corresponding author: werbicki@ualberta.ca

\section{ABSTRACT}

This essay was written for Dr. Quamen's ENGL 486 class on the Internet as Environment. Using network theory, I seek to analyze the structural characteristics of power ${ }^{1}$ and authority ${ }^{2}$ in J.R.R. Tolkien's The Lord of the Rings. I then compare my findings with H.C. Mack's parametric analysis of the texts, and suggest that both structural methodologies serve to reinforce the idea that concepts of sight and egotism play a key role in Tolkien's binary portrayal of characters as being either good or evil. The essay concludes with the suggestion that the configurations power and authority in LotR are deeply tied to Tolkien's portrayal of the nature of good and evil, and suggests further research into the question of whether such power configurations may have since become mythic tropes in Western fantasy.

\section{Introduction}

Franco Moretti's concept of "distant reading" (Distant Reading 2013) removes the reader from the standard conventions of literary analysis (what we might call 'close reading' a text's minute details) to instead view the relations between characters on a macroscopic scale. Such an analysis can provide access to a relatively untapped lens of scrutiny; I here seek to apply the concepts of distant reading and network theory to J. R. R. Tolkien's The Lord of the Rings as a method of analyzing the flow of authority and the corresponding configurations of good and evil. I first form and analyze a network of The Lord of the Rings in terms of the authority dynamics found within the forces of evil (Figure 1) and the forces of good (Figure 2). My discussion of the networks proposes that Sauron's hierarchical relationship to his forces ultimately leaves his network vulnerable to the resistance offered by the more dispersed forces of good.

I then seek to compare and contrast my visual representations to the ideas found in H. C. Mack's "A Parametric Analysis of Antithetical Conflict and Irony: Tolkien's The Lord of the Rings." Mack argues that parametric structuring allows Tolkien to portray evil as being both egocentric and in possession of 
a wide yet false vision of reality; contrastingly, good is built to be selfless and in possession of a narrow yet true vision of reality. Thus Mack's analysis grants a bottom-up understanding of how an individual's choices (or their perceived choices) and the corresponding consequences of choice fit into an "inverse pyramid" 3 split into two sides by Tolkien's good/evil binary (Mack 148). I argue that a network which analyzes the configuration of authority structures between good and evil provides a corresponding top-down reading of the text that complements and re-affirms the existence of Mack's arguments on ego and vision. This analysis does not extend to whether Tolkien himself constructed LotR in a bottom-up or topdown manner, but rather seeks to prove how two very different types of structural analysis can produce such congruent points of understanding. Regardless of Tolkien's methodology, I suggest that the structural composition of both good and evil is no accident, but actually integral to the formation of characteristics that are intrinsic to the alignments themselves.

\section{Literature review}

Applying network theory to LotR offers several new insights into the over fifty-year-old text. Although networks are generally associated with mathematical and scientific research, new attempts to provide visual data as contextual evidence are making their way into the humanities. Guido Caldarelli and Michele Catanzaro's "Networks: A Very Short Introduction" offers insight into the applicability of networks to a variety of natural and social phenomena, and also provides a number of definitions that I will draw from when analyzing my networks. Networks, according the Caldarelli and Catanzaro, form the underlying structure of what seems to otherwise be "a disordered pattern of many different interactions" (Caldarelli and Catanzaro 1). Easily identifiable networks might include a food web or a family tree. While Caldarelli and Catanzaro's ideas and terminology serve as useful reference points for our discussion, the authors' examples of applying network theory to the realm of literature are few and arguably a weaker aspect of their text.

Another prominent figure in network theory is Franco Moretti, an English professor notable for his concept of 'distant reading.' Moretti's “Network, Theory, Plot Analysis" attempts to plot the relations between the characters of Hamlet, and serves as the inspiration for my emplotment of power in LotR. For Moretti, the use of a network will "reduce the text to characters and interactions, abstract them from everything else, and this process of reduction and abstraction makes the model obviously much less than the original object" (Moretti 84). Less may be more, however, when one is attempting to succinctly visualize individual topics and relations that are bound within the confines of otherwise dense texts. The story of LotR covers 1031 pages, not including the book's appendices, as well as the wealth of information found within Tolkien's greater legendarium, and so the use of network theory to model a concept such as 'authority' is suitable, and perhaps necessary, to sift through information in terms of its relevance.

The value of network theory goes beyond simply representing; networks and their corresponding graphs can show trends and degrees of separation that might be otherwise hidden to readers. In analyzing the plot of Hamlet, Moretti claims that networks are valuable in "Making the past just as visible as the present . . Then, they make visible specific 'regions' within the plot as a whole" (Moretti 84). Much the same value can be attributed to a network on authority: not only can one see the text's authoritarian systems as a whole, but one can also identify those 'regions,' wherein authorities intersect in the form of larger groups and factions. Thus the promise of network theory is to reveal the text's otherwise hidden 'big-pictures.' On the other hand, one must still be careful because the network is not concerned with any individual's interior struggles so much as their exterior relations to all of the other characters. 
Due to network theory's penchant for overlooking individual agency, I later call upon H. C. Mack's use of parametric analysis as a means of providing a contrastingly bottom-up reading of LotR. Mack understands the world of LotR in terms of antithetical conflict; drawing from the work of Louis G. Heller and James Macris to define antithetical conflict in terms of a "confrontation" of two choices, each of which exists in a "negative relationship to the other" (Mack 121). A profound instance of antithetical conflict stems from the elves' choice to provide support in destroying the One Ring, as the destruction of the ring will also destroy their own magical sanctuary homes. This is why Lady Galadriel's test against the One Rings power is so significant; giving into the ring's temptation, and thus failing to overcome her desire for power, would have meant not only the destruction of both Sauron and his forces, but also the continued existence of elven sanctuaries such as Lothlórien and Rivendell. It is only Galadriel's wisdom that allows her to recognize such a reality would fester with the seeds of corruption, and that she herself would soon become an evil witch queen, thus renewing and perpetuating the cycle of evil. Ironically, it is only by rejecting the power to save her people that Galadriel is ultimately able to bring them to the salvation of the Undying Lands. This rejection of power by good characters is seen time and time again throughout the story.

\section{Methodology}

As noted above, the top-down lens of network theory allows one to read the text at a distance. Individual character's choices and motivations are hardly considered; a network may not clearly differentiate major characters such as Frodo and Sam from characters such as Lord Celeborn or Prince Imrahil. On the other hand, the network can also highlight the perhaps underrepresented contributions of characters. For example, the texts alone may leave many readers justifiably unaware of the extent of Aragorn's significant connections, or perhaps completely oblivious to the very existence of the Northern theatre of war. It is through the network that one can succinctly read the the broad schematics of command and gain a fuller appreciation of the widespread chaos associated with the War of the Ring. The concise format of the data can, in turn, allow us to reasonably speculate as to the connectedness of power configurations and factors such as individual and group morality.

The networks I have produced grant a general overview of the hierarchical compositions of the forces of evil (Figures $1 \mathrm{~A}$ and $1 \mathrm{~B}$ ) and the forces of good (Figure 2). The nodes ${ }^{4}$ of the networks comprise various individuals, groups, and greater armies, as well as objects that exert a corruptive influence over living creatures. Throughout this essay I will collectively refer to these bodies as actors. The actors are generally connected to each other on the basis of hierarchical power, and thus in most cases the edges ${ }^{5}$ are arrowed from authority figures towards their subordinates ${ }^{6}$. Other times the relationship between actors is less hierarchically defined, and so the edge is not arrowed but rather labelled with a defining term; for example, the relationship between Sauron and the monstrous spider Shelob is labelled as an alliance because their relationship is a twisted symbiosis: Shelob guards an entrance into Mordor and in turn Sauron occasionally feeds her orcs (Tolkien 724). Nodes such as "The White Council" in Figure 2 are colored blue because they are not actors proper, but rather provides a shortcut to represent that all linked characters are in an alliance.

The networks only grant a broad look at the dynamics of authority. Characters who die during the War of the Ring have an X marked by their name, while characters who travel to the Undying Lands are not marked with an X. When necessary, I have applied dates to any arrowed edges that connect subordinates to two or more superiors who transfer authority; Eomer, for example, takes command of the Riders of Rohan after his uncle Theoden dies to the Witch King on March 15, 3019 (Tolkien 1093). It is important to note that LotR, and indeed 


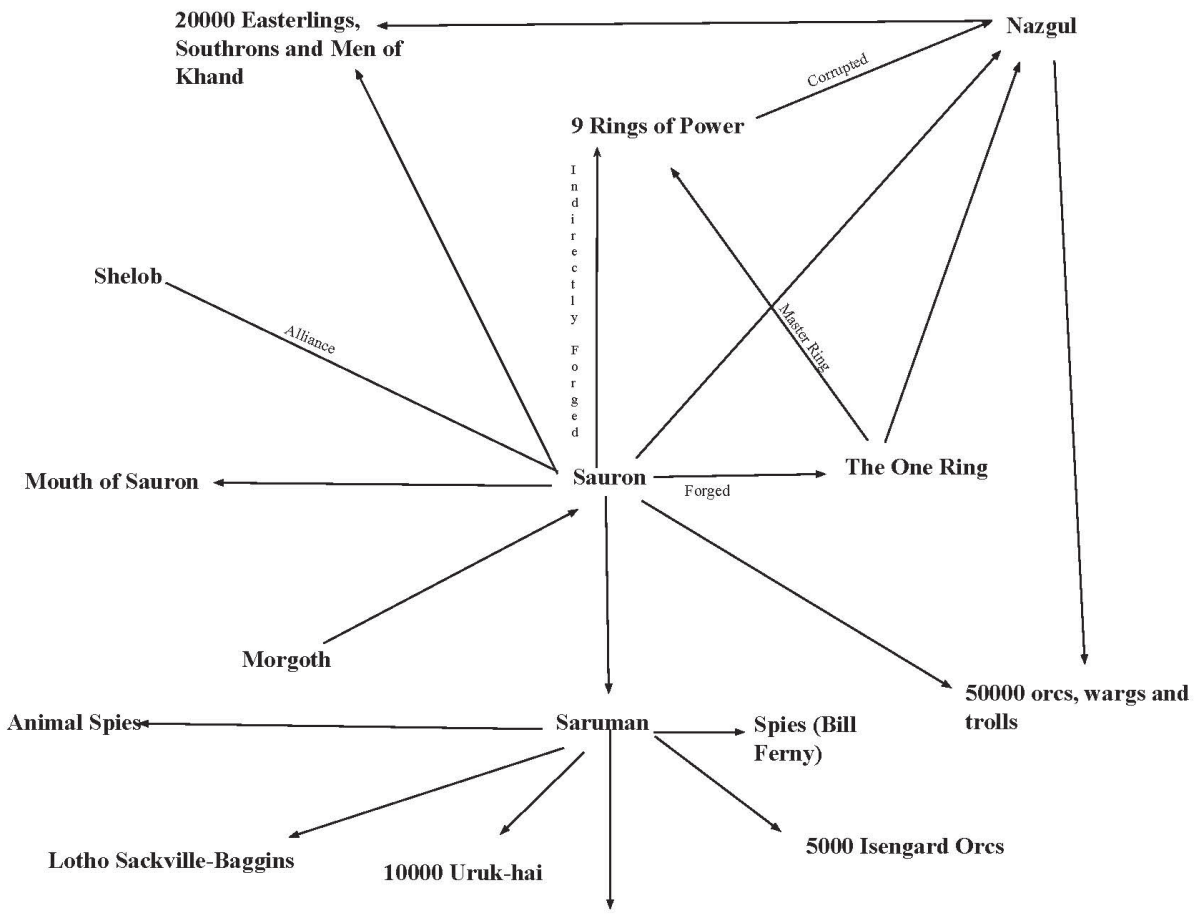

Grima Wormtongue

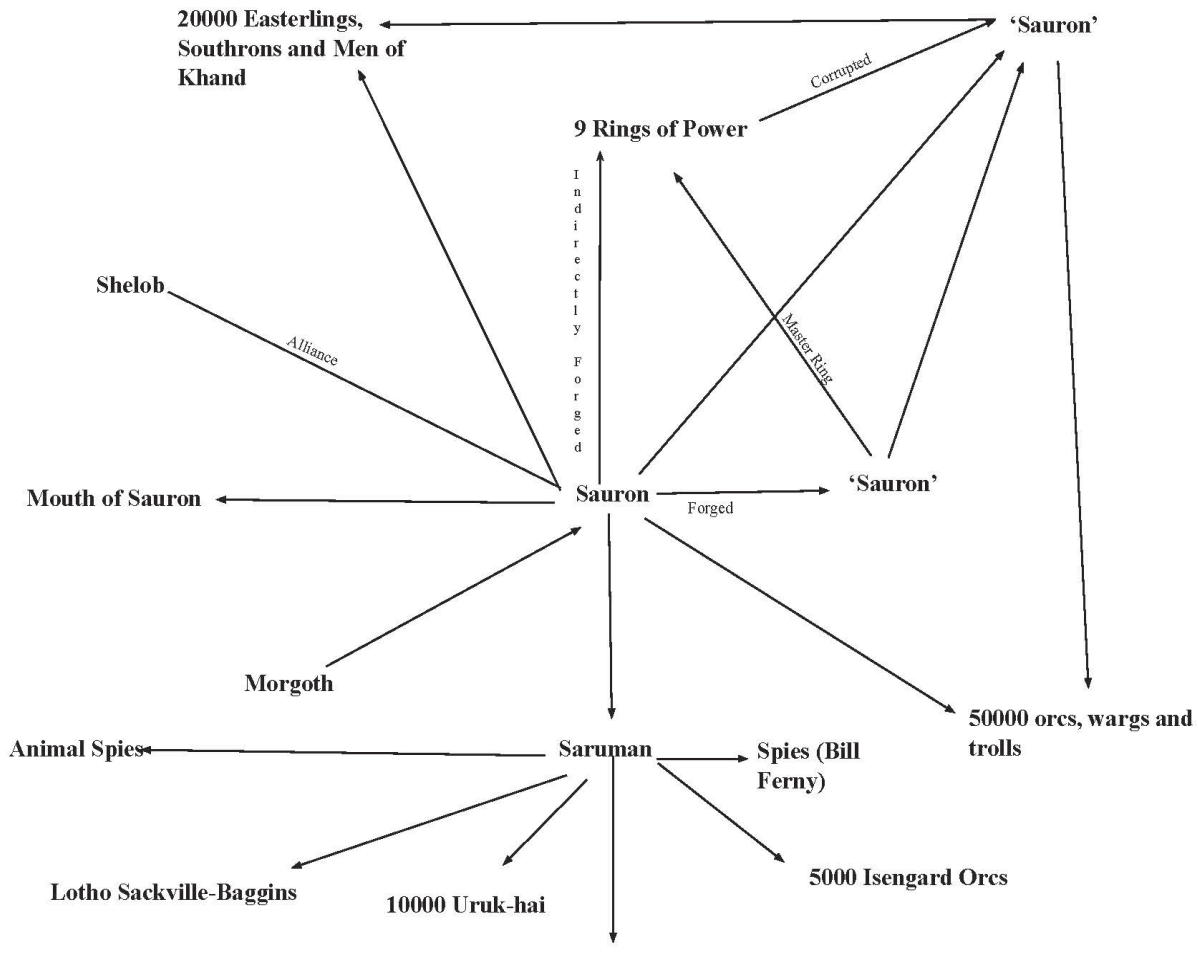

Grima Wormtongue

Figure 1: Authoritative command in the forces of evil. Version A (top) and B (bottom) 


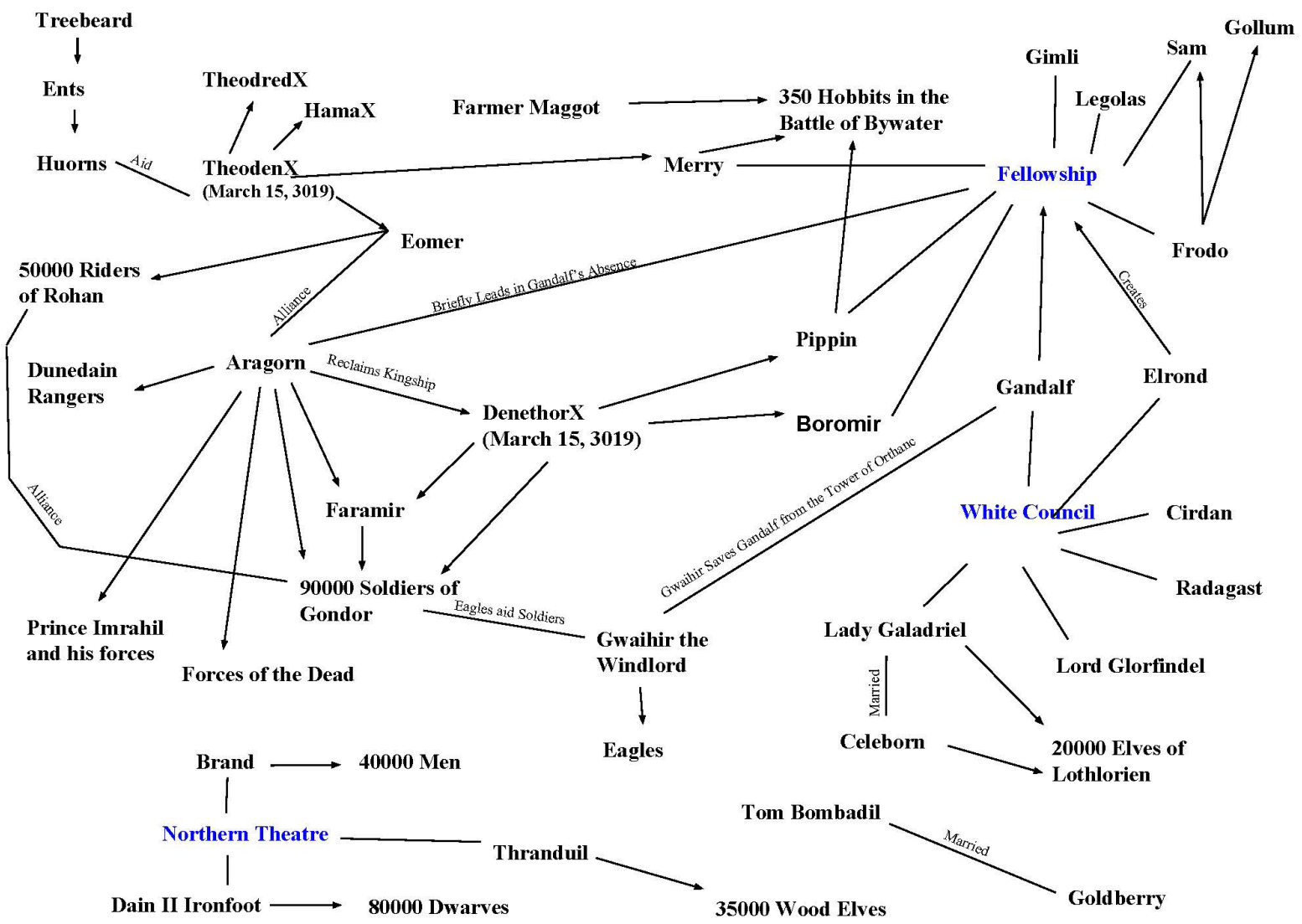

Figure 2: Authoritative command in the forces of good.

perhaps most texts, generally possess an innate bias to represent good, and confine evil creatures to the ranks of nameless hordes, and as a result the network of evil forces is likely less fleshed out than one might expect. Such a bias may skew our perception to the degree of which the forces of evil lack in complex interior structures. Sauron's army consists also of wargs and trolls, as well as a number of men in the form of Easterlings, Southrons, and Khand. Figure 1 clumps these beings into two groups, the first being the humanoid-like orcs/wargs/trolls and the second being the humans proper. We find, however, that even if we were to separate these beings into six distinct groups the larger network would remain relatively unchanged, certainly in the sense that all authority would still flow upwards towards Sauron. So while the network could be composed in ways that further divide the factions, it is impossible to escape the fact that Sauron remains the ultimate superconnector ${ }^{7}$. Furthermore, some interior politics do exist for evil; the orcish soldiers come from different clans and still possess their own agency, as shown when interior discord erupts amongst the Orcish ranks after two clans fight over Frodo's mithril: "there was fighting in the tower, the orcs must be at war among themselves, Shagrat and Gorbag had come to blows" (Tolkien 899). We are also given the proper names of a few other orcs (Gothmog is notably a lieutenant of the Witch King), but an overall hierarchy beyond Sauron --> ringwraiths --> orcs/evil underlings is largely absent.

Applying concepts of power and significance to each node is outside the networks' visuals, yet vitally important to understanding their limitations. By power I mean the perceived potential of impact that actors can have on the battle between 
good and evil, and by significance I mean the actor's actual impact on the story's events. Of course not all actors hold equal power nor significance; the 50000 Riders of Rohan, for example, are undoubtedly a more powerful and significant actor than the single figure of Hama the doorward, and yet each are given their own singular node, potentially misleading interpreters into fallacies of false equivalency. ${ }^{8}$

"Superconnectors" are defined as those areas that have a "majority of connections" (Caldarelli and Catanzaro 54). Figure 1 shows that Sauron serves as a superconnector to all other points. Saruman serves as a secondary, smaller superconnector, and the Nazgul, being Sauron's lieutenants, form another smaller hub ${ }^{9}$ of connections. Apart from these three actors the other nodes are connected to only one or two vertices, and all authority filters back to Sauron himself (aside from Sauron's dark master Morgoth, who is chained long before the War of the Ring and thus largely irrelevant to the story's plot). Sauron thus has at least an indirect control over virtually every other actor in the network, with the exception of Shelob, who serves as a tenuous ally, and the rings, whose edges I have labelled as being crafted because they are not so much subordinates to Sauron as they are extensions of his dark will.

Mack's parenthetical analysis provides a complementary bottom-up lens through which to view the text. Unlike the top-down analysis provided by network theory, a bottom-up building of events is dependant upon individual drives and desires; by examining character's struggles, motivations, and choices, Mack is able to create a map of seemingly antithetical choices and outcomes. As with network analysis, this mapping of the text constitutes an attempt to bring some degree of objective analysis to the reading.

Are the two different forms of structural analysis congruent in their findings? I believe two points that Mack raises are supported by my networks:
(1) evil possesses a wide but false vision of reality, and (2) good possesses a contrastingly narrow but true vision of reality. The first point is supported by an examination between Sauron's role as a superconnector and Mack's analysis of the Dark Lord's vision and ego. For the latter point I have used Mack's antithetical technique to craft an analysis of Aragorn, which I then compare to his role in leading a relatively distributed network of forces. If we take these characters to be representative of the values of their evil and good, then their methodology of organizing power and authority is also synonymous with the opposing alignments.

\section{Discussion}

One might argue that the fact that Sauron diffused his own power into the One Ring displays a lack of egocentrism in that his original body is weakened for the purposes of adding another node to his network. This argument, however, over-values the physical body and oversimplifies a much more complex system of power dynamics. By transferring a large part of his soul into the One Ring Sauron essentially creates a second node of himself in artefact form; the purpose of this node is to control the other rings, specifically the Nine Rings of Power given to mortal men. These mortals would eventually be corrupted into the Nazgul, and Sauron was then able to reclaim their nine rings and yet keep the Nazgul completely enslaved to his own will: "The Rings eventually left the kings spectral, invisible to all but those who could see into the wraith world, and slaves to the will of Sauron. Their lives and power became bound to Sauron's via the One Ring; as Sauron grew or diminished in power, so too did the Nazgûl" (Nazgul, The One Wiki). Thus without agency, the Nazgul become little more than further extensions of Sauron himself, and mathematically the dark lord has gained a significant net increase to his power:

Sauron's full power $=\mathrm{X}$

Power of the Nazgul $=Y$

Sauron's power after creating the One Ring $=.5 \mathrm{X}$ 
Power of the One Ring $=.5 X$

Sauron + the One Ring + the Nazgul $=.5 X+.5 X+$ $\mathrm{Y}$ or $\mathrm{X}+\mathrm{Y}$

Again, the power is diffused amongst multiple actors, but each actor is only the physical extension of one spiritual darkness; thus it is quite possible to remake the network and replace the rings and the nazgul with the name of Sauron himself, thus granting us a new and compelling vision of the authoritative hierarchy (Figure 1B). Egocentrism then becomes exceptionally clear; if we understand Figure 1B to expand the concept of 'Sauron' itself then not only does Sauron serve as an enormously massive superconnector, but we can also see that his destruction destroys virtually every other edge within the network. The only edges remaining are between Saruman and his forces, who happen to be destroyed long before Sauron's own fall.

Sauron's position of being an unnaturally authoritative superconnector causes the forces of evil to operate as a heterogeneous network. In a typical heterogeneous network the nodes prefer to connect only with other nodes that have already established many connections, thus leading to a "hierarchy" of nodes and the "rich-get-richer phenomenon" (71). The idea of individual actors having a preference is a bit misleading here because it is Sauron's top-down will that organizes his network, and yet it is nevertheless clear that the dark lord has stacked his own nodes with disproportionate power. Caldarelli and Catanzaro argue that the overall structure of such a network tends to be "virtually unaffected" when nodes are removed at random (Caldarelli and Catanzaro 97) ${ }^{10}$. This is apparent in Figure 1, wherein one could remove any node save Sauron (and to a lesser extent Saruman), and still have much the same visual left over-the network would still generally function in much the same manner. This organization makes Sauron's forces especially dangerous to the forces of good; if we were to randomly remove nodes from both networks at an equal rate, then the good forces, whose network is more homogenous, will have their network destroyed far sooner, in the majority of trials (97). This notion would be even clearer if I had not clumped large groups of actors into individual nodes; the 50000 orcs, wargs, and trolls under Sauron's command, for example, could theoretically be represented with 50000 different nodes, thus further diminishing the chances that a 'Sauron' node would be randomly selected. Of course war is generally conducted in a strategic manner, and so commanders will always seek to remove highly connected or powerful nodes, and this is how good ultimately prevails in LotR: first they remove Saruman's node and his associated forces, and then they destroy the ring, and thus Sauron, his bodies, and all edges connecting his other associated forces. Returning briefly to Figure 1B, it becomes clear how Sauron's defeat causes the total collapse of every edge in the system, as every node that we have relabeled as 'Sauron' is in some way responsible for connecting every other node together.

How does Sauron allow such a decisive strike to destroy him and his forces? He certainly had access to the resources needed to prevent his own destruction. This question leads into a discussion comparing the networks to Mack's claim that evil possesses egotistical qualities and blurred vision. Mack argues that Sauron:

cannot fathom goodness or any action which does not stem from evil ... Sauron cannot imagine that anyone would wish to destroy the Ring rather than to establish himself as another Ringlord; he, therefore, prepares for what he sees as inevitable war over possession and control of the Ring. His peril lies in the fact that the Ring is at that very moment headed toward destruction in the Crack of Doom under his very Eye-the Eye which sees only that which it expects to see (Mack 133)

In other words Sauron is entirely blinded by power: he is one of the most powerful figures of the third age, he directly commands the 
land's most powerful army, and his priority is to maintain power by squashing any who might rise against his rule. Sauron's ego thus distorts his understanding and causes him to believe that hierarchical domination is the ultimate goal of all individuals, and that the One Ring is the means by which his foes may achieve that goal. Thus does Sauron never consider the centricity of his power (his position as a massive superconnector) to be a weakness, because he cannot comprehend that any would seek the destruction of his system; the worst case scenario that he can imagine is that another being would overthrow him with the One Ring's power, but that being would eventually be corrupted and submit to the One, and so ultimately carry out Sauron's will regardless.

Mack notes that is ironic that Sauron's symbol is a great and seemingly all-seeing eye (133), and I believe this is because of his tunnel vision on the import of power leaves him blind to the fact that actions of significance can be completed by even the smallest of heroes. When Frodo destroys the One Ring he is also able to instantaneously deconstruct every version of 'Sauron' that we find in both versions of Figure 1. And because Saruman has already been defeated by this point, the destruction of the One Ring removes every remaining edge in the network!

We can compare Sauron's egotism and shortsightedness to the more lateral distribution of power found in Figure 2. Unlike the forces of evil, who are all dominated under Sauron's will, the power of the forces of good stems from their alliances against their mutual enemy. Multiple high authority figures exist and none has absolute control over all other beings; if good is to be selfless and clear-sighted then it cannot adopt its foe's tactics of outright domination; the forces of good are rather bound by alliances and their need to unite against their common foe. The largest collection of good military forces are actually found to reside in the Northern Theatre, under the command of Brand (40000 men), Dain II (80000 dwarves), and Thranduil (35000 elves). This theatre, however, is largely absent from the text proper and so will not be further detailed here. More relevant are the Riders of Rohan (50000) and the Soldiers of Gondor (90000), who individually or collectively take part in the battles of the Fords of Isen (the first and second), the Hornburg, Pelennor Fields, and the Black Gate. Other noteworthy actor armies include the ents (1000) and their huorns (10000) who take part in the Battle of Isengard and the Hornburg, the elves of Lórien (20000) who defend their home from periodic assaults, and the hobbits (350) who fight in the Battle of the Bywater.

The actor with arguably the most influence (at least in terms of commanding sheer numbers) is Aragorn, who is often forced to make difficult choices based on moral criteria. Throughout his time with the fellowship he is conflicted as to whether he should continue aiding Frodo or take up his position as king and aid the people of Gondor. It is only after Frodo and Sam break away from the rest of the group that Aragorn is finally forced to choose: "I would have guided Frodo to Mordor and gone with him to the end; but if seek him now in the wilderness I must abandon the captives to torment and death" (Tolkien 419). Ironically, it is Aragorn's choice to track Merry and Pippin which ultimately helps Frodo. Interestingly, Mack does not employ systems of antithetical structure to analyze Aragorn's choices, even though such an analysis would directly support arguments for the narrow yet selfless nature of good character's sight. Employing Mack's own method, one can create a table that relates the concept of sight to Aragorn's potential choices and their consequences. First we recognize the archistructure, which consists of Aragorn's antithetical goals and the actions needed to reach those goals. Next pseudostructure is established, which Mack defined as "the literary character's misconception of the total structure" (Mack 122). Finally comes the Alethestructure, or "the true structure which underlies the action" (122). 
Archistructure -- Aragorn's opposing choices and his methods to achieve desired ends

Possible Goals

Actions to Achieve Goals

Save Middle-earth

Follow fears (Frodo is in danger)

Save Merry and Pippin

Follow heart (Merry and Pippin are in danger)

Pseudostructure -- Aragorn's misconception of his choices

Possible Goals

Actions to Achieve Goals

Save Middle-earth

Find Frodo and help him destroy the One Ring

Save Merry and Pippin

Track and slay the orcish captors

Alethestructure -- "true structure which underlies the action" (Mack 122)

Possible Goals

Actions to Achieve Goals

Save Middle-earth

Save Merry and Pippin

Reclaim kingship and draw Sauron's eye away from Frodo

Do nothing

By choosing to follow his heart and save Merry and Pippin, Aragorn is forced to waylay his fears and put his faith in Frodo. The irony of the situation is apparent on multiple fronts: firstly, by the time Aragorn, Legolas, and Gimli reach Merry and Pippin they find the hobbits to no longer be in need of saving. Frodo and Sam, meanwhile, are still desperately struggling towards Mordor. Secondly, however, the act of following Merry and Pippin places Aragorn in the path of Gandalf, who in turn leads him to Rohan and later Gondor. This in turn leads Aragorn to fight in the Battle of Pelennor Fields and then reclaim his kingship, and the act of becoming king allows Aragorn to muster the remaining forces to draw Sauron's eye, thus finally allowing Frodo and Sam to sneak past the dark lord and destroy the One Ring. Thus, it is ironically Aragorn's initial choice to save Merry and Pippin which ultimately leads to him being able to help save Middle-earth. Conversely, it follows that if Aragorn had initially followed his fears and attempted to track Frodo, his own limited power would not have been enough to overcome Mordor and thus the quest would have failed. Despite what the archistructure and pseudostructure inform us, Aragorn's choices were never actually antithetical! This analysis reaffirms Mack's arguments that good is not only selfless ( must not abandon my doomed companions), but also relatively narrow-sighted (my actions will prevent me from aiding the ring-bearer). One of the limitations of the top-down network is that it does not so easily display this kind of logic which ultimately builds up the connection between choice and virtue, because, as I have mentioned above, the network is not concerned with any individual actor's interior struggles so much as their exterior relations to all other nodes.

Moving forward, one can see that selflessness and faith are also key to the White Council. The faction composes itself with some of the most individually powerful figures in Middle-earth, yet rarely makes claims to authority over other peoples. Rather, the council acts to unite the various peoples towards greater purposes. Elrond, for example, is the one who calls the Council of Elrond, which brought individuals together from across the realm and united them in the Fellowship of the Ring. Gandalf is even more interesting, as he is present for much of the text and yet does not possess a large number of authoritative links. Despite being a being of incredible power Gandalf only takes authority twice: first, over the initial fellowship, and then later for a brief time over the forces of Minas Tirith, after Denethor goes mad with grief. Nor does Gandalf covet authority; his leadership over the fellowship ends when he selflessly sacrifices himself against the balrog (Tolkien 331), and he himself crowns Aragorn as king (968). Furthermore, Gandalf initially declined the position of leadership over the white council (Gandalf, The One Wiki) and absolutely refuses to use the One Ring for fear that its influence over his power would 
lead to the downfall of Middle-earth. Thus Gandalf exudes humility, and his presence serves to unite the forces of good rather than control them like pawns; upon Shadowfax he races to give Theoden and later Denethor council, as well as organize the Rohan soldiers to defend Helm's Deep.

Being a Maiar sent to Middle-earth to oppose the threat of Sauron, Gandalf can be understood to literally exist as an avatar working on behalf of some force of greater good (whether this good be in the form of the Valar or Eru Illúvatar himself). The scope of this paper is not such that I can investigate Tolkien's expanded universe and Christian influences in great detail, and so this paragraph will be limited to a few points of speculation. If Tolkien presents goodness itself as a stable and universal condition (under the control of his god Eru), and if Gandalf's transformation into Gandalf the White represents his fusion with the principles of this Goodness, then it follows that his diplomatic uniting of various peoples is a act of service to Eru and Goodness. Thus one might reasonably surmise that Tolkien's principles of Goodness at least in part consist of the conscious choice to create some balance between willing cooperation and self-determination, both at the individual and collective level. The lateral distribution of Figure 2 supports this theory, and is contrasted by the evil hierarchical dominion showcased in Figure 1. As another very small aside, one might also suggest that the Hobbits of The Shire begin the text removed from the other races, and it is only through their journey that the four hobbit protagonists are able to return to The Shire and lead their people in a self-determined resistance against Saruman's hostile takeover.

\section{Conclusion}

While both network theory and antithetical structuring seek to add a layer of objective evidence to literature studies, neither approach, used separately nor together, gives a conclusive picture of a work in its entirety. Both theories are ultimately based in structurality and subject to its criticisms, because the authenticity of the proposed structure (the configuration of the network or the parameters of parenthetical analysis) is constantly debatable. There are all too numerous ways in which these networks could be read and reconfigured. What I have attempted to do is give a sample of how network theory can complement and reaffirm other structural discourses. Of course the inverse is also true; it could just as easily be said that Mark's antithetical structure analysis could be used to complement and reaffirm network theory. My own conclusions on the cohesion between the theories may also be the result of unconscious biases, and I admit it may be possible that one could construct a similar network which suggests conclusions on vision and ego that do not conform to Mack's ideas. As with all theories one must use their discretion when accepting the presented data.

What is important in the case of this paper, however, is that network theory and antithetical analysis do seem to mutually support similar conclusions towards the vision and ego of good and evil characters. Disagreements between different types of structural analysis could highlight the weaknesses and limits of the analyses themselves, especially when comparing top-down and bottom-up approaches. Future investigations into the structural network of LotR might do well to link the networks of good and evil and seek to understand how the text handles issues of corruption and redemption. Gollum, Frodo, and Saruman would be the most immediately valuable characters in such a study. The concepts of authority and power are but two of a wide range of possible subjects that a network could cover. The role of Gandalf as a messenger and resistance organizer would be, for example, more pronounced in a network that only focused its analysis upon character interactions. Combining network theory with other non-structural analysis would present some interesting opportunities to evaluate the text (for example, perhaps a networked map of the female character's 
interactions can be drawn and combined with a feminist reading in order to comment upon Tolkien's portrayal on female agency).

The analysis of power hierarchies in epic fantasy provides an interesting look into the moral underpinnings of the author's work; Tolkien, both explicitly and implicitly, has his good characters continuously deny power. The ends do not justify the means; to save humanity paradoxically means to reject the item that could destroy humanity's enemies. The forces of good possess a homogeneous power distribution exactly because no single being takes the ring and becomes the egocenter of all power. It would be interesting to study how such understandings of power and authority may have been represented over time in other fantasy writings. A central question then might be if Tolkien's work continues to inform the power structures of good and evil factions in more modern text; for example, one might compare Sauron's armies and corrupting rings to the organization of Voldemort's Death Eaters and use of horcruxes in the J.K. Rowling's Harry Potter series. If such a network produced similar patterns in power structures we might understand how a fantasy organization's structurality informs our common conceptions of their intrinsic morality. 


\section{Notes}

1. I use the term "power" to denote the perceived impact that an individual character's abilities and resources might potentially have on the outcome of the story's events. An example of a powerful character is Sauron; despite the fact that he is ultimately defeated he undoubtedly holds relatively unmatched physical and magical prowess, as well as legions of soldiers under his command. Frodo, on the other hand, is one small hobbit and not exactly powerful. The irony of power is discussed at length in my discussion section.

2. "Authority" here connotes the existence of a chain of command that may exist between two or more characters.

3. The base of Mack's "Inverse Pyramid" is where a character's initial significant choice is made. Mack describes characters choices to consist of two or more antithetical options (Mack 121). Thus a theoretical map of potential choices and consequences grows always upward and outward. Because of the antithetical nature of choice, however, the picking of one option seemingly precludes the ability to obtain the results desired by making a different choice, and thus a character's actual realized path of choice and consequence can only travel in a linear and upward (though perhaps unexpected) manner. Mack also describes the pyramid as having both a light and dark side, and in doing so suggests that characters make choices based upon their alignment to good/evil, which in turn is based upon how they balance their sight and understanding of future events.

4. A node describes any named point of the network that may be connected to other nodes by edges.

5. An edge is the line that connects two nodes together.

6. I use the term subordinate to denote any actor who is under the authority of another actor, and have used my discretion when the authoritative relationship is not wholly clear.

7. A superconnector refers to any actor in a network who is connected by edges to a relatively high number of other individuals. Sauron is described as a superconnector because he is, on the basis of authority, at least indirectly connected to every other individual or group within his network with minimal degrees of separation.

8. The visual data may lead one to falsely view an actor such as Hama as being equally powerful and/or just as significant as major armies or the heroic main characters. Discretion is needed to analyze each actor's power and significance beyond their placement in the network itself. Given the sheer volume of actors, such a task is beyond the purview of this essay.

9. Like a superconnector, a hub refers to any node that has a large number of vertices.

10. Random in this case means arbitrary; each individual node and their corresponding edges would have an equal chance of being removed from the greater system. 


\section{Works Cited}

Caldarelli, Guido and Michele Catanzaro. "Networks A Very Short Introduction." Oxford University Press, 2012.

Mack, H. C. "A Parametric Analysis of Antithetical Conflict and Irony: Tolkien's The Lord of the Rings." Word, Vol. 31, No. 2, 1980. Routledge, 2015.

Moretti, Franco. Distant Reading. Verso, 2013.

---. "Network, Theory, Plot Analysis." 2011.

The One Wiki to Rule them All. Fandom Wikia. http://lotr.wikia.com/wiki/Main_Page. Accessed Sunday October 15, 2017.

Tolkien, J. R. R. The Lord of the Rings. HarperCollinsPublishers, 2007. 